\title{
Prediction of Coal and Gas Outburst Risk in West No. 2 Mining Area of Weijiadi Coal Mine
}

\author{
Jufeng Zhang ${ }^{1,2, a, ~}$, Ruiyun Wang ${ }^{3, \text { b }}$, Fengfeng Yang ${ }^{1}$, Lan Yu ${ }^{1}$, Chao Zheng ${ }^{1}$, Rili Yang ${ }^{1}$, \\ Jianjiang Zhang ${ }^{3}$, Zaiquan Miao ${ }^{3}$ \\ ${ }^{1}$ College of Energy Engineering, Longdong University, Qingyang 745000, China \\ ${ }^{2}$ School of Resource, Environment and Safety Engineering, Hunan University of Science \\ and Technology, Xiangtan 411201, China; \\ ${ }^{3}$ Weijiadi Coal Mine of Gansu Jingyuan Coal and Electricity Co., Ltd. Baiying 730913, China \\ ajufeng6100229@126.com, ${ }^{b} 422622510 @ q q . c o m$
}

Keywords: gas pressure; gas content; coal and gas outburst; risk prediction

Abstract: Through the collection and arrangement of gas data in the West No.2 District of Weijiadi Coal Mine and the determination of gas parameters on site, this paper measures and uses the Langmuir equation to verify gas pressure in mining area. Based on comprehensive consideration of the coal body structure and coal seam gas parameters, according to coal and gas outburst sensitive indicators and critical values, the coal and gas outburst risk in $1 \#$ coal seam and $3 \#$ coal seam in $\mathrm{Xi} 2$ mining area was predicted. The results show that No coal and gas outbursts are found in the West No.2 District.

\section{Introduction}

Coal and gas outburst is a kind of mine gas dynamic phenomenon which is extremely serious and is the result of the comprehensive action of factors such as ground stress, gas and coal physical and mechanical properties. Coal and gas outburst accidents cause serious losses to life and property safety of mines and workers, and are one of the most important indicators affecting mine safety production and technology and economics [1]. The "Prevention of Coal and Gas Outburst Regulations" requires the implementation of two "four-in-one" comprehensive anti-outburst measures, requiring regional measures to be implemented first, partial measures to be supplemented, putting prominent risk prediction at the top priority, and indicators based on outburst risk prediction. The critical value determines the prominent danger [2].

Many scholars proposed a variety of coal and gas outburst risk prediction methods. Shen Zhiwei and Wang Enyuan et al. [3] proposed a coalmine and gas outburst risk prediction method based on the mutation progression method. Liang Yueqiang et al. [4] applied the projection pursuit method. The clustering method was used to construct the projection pursuit clustering model for coal and gas outburst risk prediction. Many scholars also proposed the "trival method" [5], expert statistics method [6], mathematical statistics [7], and fuzzy Degree theory [8], grey correlation method [9] and other methods to study prominent sensitive indicators and their critical values have achieved good results. This article is mainly to use the single index method and the comprehensive index method to forecast the outburst risk in the West No.2 mining area of the Weijiadi coal mine. This 
will further improve the prediction reliability of coal and gas outbursts, and has important economic and safety implications for ensuring the safety of mine production.

\section{Overview}

\subsection{Overview Coal Mine}

Weijiadi Coal Mine is the backbone mine of Jingyuan Coal Industry Co., Ltd. The mine is a coal and gas outburst mine. There have been 11 gas dynamic phenomena. The gas content in the coal seam is 9.22 to $10.17 \mathrm{~m}^{3} / \mathrm{t}$, the permeability coefficient of the coal seam is 0.213 to $0.7 \mathrm{~m}^{2} / \mathrm{MPa}^{2} \cdot \mathrm{d}$, and the gas emission from the $100 \mathrm{~m}$ hole is taken. For the range of 0.152 to $0.278 \mathrm{~m}^{3} / \mathrm{min}$, the exhaust gas flow attenuation coefficient of the 100 meters borehole is 0.032 to $0.053 \mathrm{~d}^{-1}$, and the coal seam is soft and has poor air permeability, belonging to a barely extractable coal seam.

\subsection{Overview of West No.2 District}

West Second Mining Area is the continuous mining area of Xi First Mining Area. It is connected to the West First Mining Area in the east, the coal broken line of the $F_{1-2}$ fault group is in the south, and the IX exploration line is adjacent to the Dashuitou Mine in the west, and $\mathrm{F}_{3}$ is in the north. The reverse fault coal-breaking intersection and the fault-extinguishing extension line are bounded. The average east-west length is $2200 \mathrm{~m}$, the north-south inclination is $900 \mathrm{~m}$, and the mining area is 1.98 million square meters.

\section{Measurement of Basic Gas Parameters in West No.2 District}

\subsection{Measurement of Coal Seam Gas Pressure}

\subsubsection{Measurement Method}

The pressure tap hole is formed on a stable rock formation (or coal seam). It requires that the drilling site is not less than $20 \mathrm{~m}$ from the drilled hole. There is no other drilling hole in the drilling site. The adjacent prediction hole opening point is more than $1 \mathrm{~m}$ apart. Points should be more than $10 \mathrm{~m}$ apart.

Sealing pressure measurement chooses ACW-1 type mechanical hole sealer to seal the hole or polyurethane grease to match the expansion hemp cement sealing hole, but it must be strictly controlled, the sealing hole is tight and the length is not less than $8 \mathrm{~m}$.

\subsubsection{Measurement Location and Data}

From 2003 to the present, a total of 8 cross-cuts were made at Shimen, and the original coal seam gas pressure was measured. The gas pressures of the highest coal seams in the first and second coal seams were measured at 16 measuring points, $\mathrm{P}=0.52 \mathrm{MPa}$, and the maximum coal seam gas pressure at the third coal seam was $\mathrm{P}=0.46 \mathrm{Mpa}$.

A total of 32 pressure measuring points and 42 pressure measuring holes were arranged in the West Second Mining Area. The maximum gas pressure in a coal seam was determined to be $\mathrm{P}=0.52 \mathrm{Mpa}$, and the maximum gas pressure in the third coal seam was $\mathrm{P}=0.46 \mathrm{Mpa}$.

\subsubsection{Gas Pressure Calculation and Verification}

According to the industrial analysis of the coal seam in the mining area, the pore volume, the apparent density, and the measured gas content of the corresponding area, the gas pressure is 
calculated using the Langmuir equation. The formula is as follows:

$$
X=\frac{\mathrm{ab} P}{1+b P}+\frac{1}{1+0.3 M_{a b}}+\frac{10 k P}{r}
$$

In the formula, The X-gas content, $\mathrm{m} 3 / \mathrm{t}$, the direct top zone of fine sandstone sandwiched mudstone and the direct top zone of middle sandstone are respectively 8.72 and 7.64;

$\mathrm{P}$-coal gas pressure, MPa;

A-adsorption constant, $\mathrm{m}^{3} / \mathrm{t}, \mathrm{a}=30.1205$;

B-adsorption constant, MPa-1, b=0.0335;

$\mathrm{M}_{\mathrm{ad}}$-coal moisture content, \%, actual measured value is 0.95 ;

$\mathrm{K}$ - coal pore volume, the measured value is 0.101 ;

$\mathrm{R}$-apparent density of coal, $\mathrm{t} / \mathrm{m} 3$, actual measured value, 1.39

Substituting each value into the above formula, the gas pressures in the coal seams of the fine sandstone-clad mudstone immediate top zone and the middle sandstone direct top zone are 0.605 $\mathrm{MPa}$ and $0.51 \mathrm{MPa}$, respectively.

\subsection{Determination of Coal Seam Gas Content}

In December 2016, in the 2107 return air slot 15\# drill field and 2304 air return slot 470m, the construction boreholes respectively collected coal seams of the first and third coal seams and measured the gas content of the coal seams, and found that the coal seam gas content was $5.27 \mathrm{~m}^{3} / \mathrm{t}$, $6.53 \mathrm{~m}^{3} / \mathrm{t}$, with methane content of $4.53 \mathrm{~m}^{3} / \mathrm{t}$ and $5.64 \mathrm{~m}^{3} / \mathrm{t}$, respectively.

\subsection{The Initial Speed Indicators of Gas Emission}

In December 2016, in the 2107 return air slot 15\# drill field and 2304 air return slot 470m, the first and third coal seam coal cores were drilled to measure the initial velocity of gas emission, and the first and third coal seam gas emission initials were obtained. The speeds were $7.108 \mathrm{mmHg}$ and $8.561 \mathrm{mmHg}$ respectively, and the initial speeds of carbon dioxide emission were $6.82 \mathrm{mmHg}$ and $6.284 \mathrm{mmHg}$, respectively.

\subsection{Coal's Coefficient of Solidity}

The firmness coefficient of the coal used in the design of the mining area is 0.5 to 1.0. In November 2016, Ningxia Coal Quality Inspection Co., Ltd. determined that the solidity coefficient of 2107 working face in the West No. 2 Mining Area of our mine was 0.65; in December 2016, Jintai, Lanzhou Mine Safety Products Inspection and Inspection Co., Ltd. determines the coefficient of solidification of coal on the working face of No. 2304 in the West Second Mining Area of 0.71.

\section{Work Face Highlights Risk Prediction}

\subsection{Single Index Method Forecast Results}

The single indicators for predicting coal seam outburst risk include the type of coal damage, initial gas velocity $(\Delta \mathrm{P})$, coal's coefficient of firmness (f) and coal seam gas pressure $(\mathrm{P})$. The critical values of the individual indicators for predicting coal seam outburst risk are shown in Table 1. What needs special emphasis is that only when all the individual indicators reach or exceed the corresponding thresholds in Table 1, the working face will have the danger of gas outburst.

Based on the gas outburst risk indicators measured in the first and third coal seams in the West 
Second Mining Area of the Weijiadi Coal Mine, and combined with the gas-basis parameters of each coal seam, the individual risk of coal seam outburst is calculated.

Table 1 Single Indicators for Outburst Coal Seam Identification in Weijiadi Coal Mine

\begin{tabular}{ccccc}
\hline $\begin{array}{c}\text { Coal } \\
\text { seam }\end{array}$ & $\begin{array}{c}\text { destruction } \\
\text { type }\end{array}$ & $\begin{array}{c}\text { Gas emission initial velocity } \\
(\Delta \mathbf{p})\end{array}$ & $\begin{array}{c}\text { Coal's firmness } \\
\text { coefficient } \mathbf{f}\end{array}$ & Gas pressure $\mathbf{P}$ (MPa) \\
\hline 一 & III $\sim \mathrm{V}$ & $7.108 \leq 10$ & $0.65>0.5$ & $0.52<0.74$ \\
三 & III $\sim \mathrm{V}$ & $8.561 \leq 10$ & $0.71>0.5$ & $0.46<0.74$ \\
\hline
\end{tabular}

According to the actual observation in the West No. 2 mining area, the single indexes of No. 1 and No. 3 coal seams do not meet the conditions required for the occurrence of gas outburst: the damage type of No. 1 seam coal is III to V partial V, and the average initial velocity of gas emission is $\Delta \mathrm{P} .=7.108<10$, the average firmness coefficient of coal is $\mathrm{f}=0.65>0.5$, the maximum gas pressure level of coal seam is 0.52 , and is less than $0.74 \mathrm{MPa}$; the damage type of coal seam $3 \#$ is III V class partial $\mathrm{V}$, and the average initial velocity of gas emission is $\Delta \mathrm{P}=8.561<10$, the average firmness coefficient of coal is $\mathrm{f}=0.71>0.5$, and the maximum gas pressure level in coal seam is $0.46<0.74 \mathrm{MPa}$. Therefore, there is no risk of coal and gas outburst in the West Second District.

\subsection{Comprehensive Index Method}

At present, one of the important methods for prediction of coal and gas outburst in the coal seam region also makes the regional forecasting technology in China to quantify qualitatively from the geostatistical method [9-10]. Considering coal seam gas pressure $\mathrm{P}$, initial gas velocity $\Delta \mathrm{P}$, coal's sturdiness coefficient $\mathrm{f}$, coal seam outburst risk comprehensive index $\mathrm{D}$, and coal's outburst risk comprehensive index $\mathrm{K}$, the outburst risk in the coal seam area is predicted.

$$
\begin{gathered}
D=\left(\frac{0.0075 H}{f}-3\right)(P-0.74) \\
K=\frac{\Delta P}{\mathrm{f}}
\end{gathered}
$$

One of comprehensive indicators of D-coal's outburst risk; K-synthetic index 2; H-mining depth, $\mathrm{m}$; f-coal soft slicing average firmness coefficient; P-coal gas pressure, taking two pressure taps The maximum value of gas pressure (absolute pressure value), MPa; The initial velocity index of gas emission of coal soft layered coal.

Table 2 shows the critical values of the comprehensive indicators $\mathrm{D}$ and $\mathrm{K}$ for predicting outburst risks.

Table 2 Calculation results of coal seam outburst risk comprehensive index

\begin{tabular}{cccc}
\hline Coal seam & Coal depth (m) & $\begin{array}{c}\text { Comprehensive index } \\
\text { (D) }\end{array}$ & $\begin{array}{c}\text { Comprehensive } \\
\text { index (K) }\end{array}$ \\
\hline 三 & 430 & $0.17 \leq 0.25$ & $18.62 \leq 20$ \\
三 & 500 & $0.24 \leq 0.25$ & $19.34 \leq 20$ \\
\hline
\end{tabular}

After calculation, the calculation results of coal seams D and K in Xi II mining area are shown in Table 2. From Table 2, it can be seen that the calculated $\mathrm{D}$ and $\mathrm{K}$ values of the coal seam outburst risk are all less than the predicted critical value, and there is no possibility of coal and gas outburst.

\section{Conclusion}

(1) The coal and gas outburst risk predictions for No. 1 and No. 3 coal seams in Xi 2 mining area were respectively conducted using the single index method and the comprehensive index method. 
The results show that there is no risk of coal and gas outburst in No. 1 and No. 3 coal seams in Xi 2 mining area.

(2) In order to avoid the threat of gas accidents to human life and property, it is recommended to strengthen the implementation of gas drainage measures during roadway excavation in the mining area and the mining of the working face and to make safety protection measures.

\section{Acknowledgments}

This work was financially supported by 2018 Gansu Provincial Safety Science and Technology Project[GAJ00011] and Longdong University Youth Science and Technology Innovation Project[XYZK1610] fund.

\section{References}

[1] Nie Baisheng, He Xueqiu, Wang Enyuan, et, al. Present Situation and Progress Trend of Prediction Technology of Coal and Gas Outburst[J]. China Safety Science Journal,2003,13(6):40-43.

[2] Wu Caifang, Zeng Yong, Qin Yong. The Application of the Analytic Methods of Neural Networks to Gas-Forecasting field[J]. Advance in Earth Science,2004,19(5):860-866.

[3] Shen Zhiwei, Wang Enyuan, Niu Yue. Prediction of Coal and Gas Outburst Based on Catastrophe Progression Method[J]. Industry and Mine Automation,2015,41(5):29-34.

[4] Liang Yueqiang, Lin Chen, Gong Weidong, et al. Application of projection pursuit cluster method in risk prediction of coal and gas outburst[J]. Journal of Safety Science and Technology,2017,13(1):46-50.

[5] Wang You'an, Wang Kuijun. Study in the method of determining the face outburst danger prediction sensitive index[J]. Safety in Coal Mines,1991(10): 9-14.

[6] Zhou Songyuan. Determination of coal and gas outburst sensitivity index and critical value[J]. Hunan Coal Science \& Technology,1995(9): 26-29.

[7] Sun Dongling. Discuss and attempt on method of determination coal and gas outburst sensitivity index and critical value[J]. Coal Engineer,1996(4):3-7.

[8] Cheng Wuyi, Luan Yongxiang, Deng Quanfeng. Study on method of determination coal and gas outburst critical value of prediction index[J]. Safety in Coal Mines, 1996(10):12-17.

[9] Xiong Yaxuan. Research on determining critical index of prediction of coal and gas outburst in the face[D]. Jiaozuo: Henan Polytechnic University, 2005. 